\title{
Attachment and non-suicidal self-injury among young adolescents: The indirect role of behavioral problems
}

Matthew Cassels, Imke Baetens, Paul Wilkinson, Karel Hoppenbrouwers, Jan R. Wiersema, Karla Van Leeuwen \& Glenn Kiekens

To cite this article: Matthew Cassels, Imke Baetens, Paul Wilkinson, Karel Hoppenbrouwers, Jan R. Wiersema, Karla Van Leeuwen \& Glenn Kiekens (2018): Attachment and non-suicidal self-injury among young adolescents: The indirect role of behavioral problems, Archives of Suicide Research, DOI: $10.1080 / 13811118.2018 .1494651$

To link to this article: https://doi.org/10.1080/13811118.2018.1494651

Accepted author version posted online: 17

Aug 2018.

Submit your article to this journal ${ }^{\top}$

ఋ Article views: 9

View Crossmark data ¿ 
Attachment and non-suicidal self-injury among young adolescents:

The indirect role of behavioral problems

Matthew Cassels ${ }^{1 *}$, Imke Baetens ${ }^{2 *}$, Paul Wilkinson ${ }^{1}$, Karel Hoppenbrouwers ${ }^{3}$, Jan R.

Wiersema $^{4}$, Karla Van Leeuwen ${ }^{5}$, Glenn Kiekens ${ }^{6}$

*Co-first authors

Authors affiliations

${ }^{1}$ Department of Psychiatry, University of Cambridge, UK.

${ }^{2}$ Lifespan and Clinical psychology Research Group, Vrije Universiteit Brussel, Belgium.

${ }^{3}$ Centre for Environment and Health, Department of Public Health and Primary Care, KU

Leuven, Belgium.

${ }^{4}$ Department of Experimental Clinical and Health Psychology, Ghent University,

Belgium.

${ }^{5}$ Parenting and Special Education Research Group, KU Leuven

${ }^{6}$ Psychiatry Research Group, Department of Neurosciences, KU Leuven, Belgium.

Corresponding author: Prof. dr. I. Baetens - Vrije Universiteit Brussels, Clinical and Lifespan Psychology, Pleinlaan 2, 1050 Brussels, Belgium - imke.baetens@vub.be

Word count: 2019

Key words: self-injury, self-harm, young adolescents, attachment, behavioral problems 
Objective: Non-suicidal self-injury (NSSI) often occurs before age 15, yet the majority of research on risk factors for this dangerous behavior has focused on older samples. Insecure attachment has been previously identified as a risk factor for both NSSI and behavioral problems, and behavioral problems appear to be particularly associated with NSSI among young populations. Redressing the lack of young adolescent NSSI research, the present study uses longitudinal data from a sample of young adolescents to test a model in which insecure attachment acts as a prospective risk factor for NSSI via emotional and behavioral problems.

Methods: Data on NSSI, child-mother attachment, and emotional and behavioral problems were collected from 559 (41.1\% male) Flemish adolescents when they were 13 years old $(M=12.71, S D=0.32)$, and again one year later. Insecure attachment was measured using maternal items on the Experiences in Close Relationships - Revised Child scale. Psychological adjustment was assessed with the Strengths and Difficulties Questionnaire.

Results: We found that anxious and avoidant attachment were indirectly associated with NSSI through behavioral problems but not through emotional problems.

Conclusions: Findings highlight the role of behavioral problems as a risk factor for NSSI in early adolescence, a rarely studied developmental period during which NSSI often first starts. Findings suggest that one possible pathway for the attachment-NSSI association 
among young adolescents is through behavioral problems. Therapies that improve childparent attachment may reduce NSSI among young adolescents both directly, and indirectly by improving behavioral problems.

Non-suicidal self-injury (NSSI), defined as "the direct, deliberate destruction of one's own body tissue in the absence of suicidal intent" (Nock \& Favazza, 2009, p. 9), is not only inherently dangerous but is also prospectively associated with a number of other negative outcomes, including higher risk of mental illness and suicide (Franklin et al., 2017; Wilkinson, Kelvin, Roberts, Dubicka, \& Goodyer, 2011). Rates of NSSI peak during mid-adolescence at around $18 \%$ for lifetime prevalence in community samples (Muehlenkamp, Claes, Havertape, \& Plener, 2012; Swannell, Martin, Page, Hasking, \& St John, 2014), however, a significant proportion of young people report an onset before age 15 (Gandhi et al., 2016; Plener, Schumacher, Munz, \& Groschwitz, 2015). Given that an earlier onset is related to more severe NSSI (Ammerman, Jacobucci, Kleiman, Uyeji, \& McCloskey, 2017), identifying risk factors of NSSI during early adolescence will provide valuable insight into the etiology of NSSI in general. Yet there have been few longitudinal studies capable of identifying prospective risk factors for early onset NSSI (e.g., female gender, emotional and behavioral problems; see Hankin \& Abela, 2011; Sourander et al., 2006; Tatnell, Hasking, Newman, Taffe, \& Martin, 2016).

One risk factor that seems robustly related to NSSI among young adolescents is insecure child-parent attachment (Tatnell et al., 2016; Tatnell, Kelada, Hasking, \& Martin, 2014; Yates, Tracy, \& Luthar, 2008). However the pathways by which attachment is associated with NSSI at this young age are unclear. While previous 
longitudinal work suggests that intrapersonal factors like psychological distress may mediate the association between insecure attachment and NSSI among young adolescents (Tatnell et al., 2014), cross-sectional evidence suggests that behavioral problems may be particularly salient to NSSI in this age group (Lundh, Karim, \& Quillish, 2007). The fundamental concept of attachment centers on infants' perceptions of their parents' accessibility and responsiveness to their needs, demands, and communications such as crying (Bowlby, 1988). From these early interactions, children learn to regulate their behaviors and emotions (Cozolino, 2014; DeKlyen \& Greenberg, 2008). As insecurely attached children's distress is repeatedly left unresolved or even aggravated by their attachment figures, development of their own abilities to regulate emotions may be impaired (Moretti \& Peled, 2004). Poor emotional regulation has in turn been found to predict of NSSI (Claes, Houben, Vandereycken, Bijttebier, \& Muehlenkamp, 2010; Klonsky, 2009), and people who engage in NSSI often have problems with both regulating emotional responses and tolerating intense emotions (Gratz \& Roemer, 2008; Klonsky, 2007). For these people, intense emotions may override behavioural controls and NSSI may be an effective means of diminishing aversive symptoms by regulating these emotions.

Among young adolescents, insecure attachment is associated not only with NSSI, but also with emotional problems such as symptoms of depression and anxiety (Irons \& Gilbert, 2005; Muris, Meesters, van Melick, \& Zwambag, 2001; Papini \& Roggman, 1992), and behavioral problems (Fearon, Bakermans-Kranenburg, van IJzendoorn, Lapsley, \& Roisman, 2010), such as trouble following rules, or getting in fights with others. In turn, both emotional and behavioral problems are prospective risk factors for 
NSSI among young adolescents (Sourander et al., 2006; Tatnell et al., 2016). Thus, both emotional and behavioral problems may represent pathways through which insecure attachment increases the risk for early onset NSSI (Gandhi et al., 2016; Hallab \& Covic, 2010; Kimball \& Diddams, 2007). However, no longitudinal study has considered the indirect role of both emotional and behavioral problems together in the attachment-NSSI association among young adolescents. Addressing this significant gap in the literature could elucidate intermediary processes through which insecure attachment is associated with NSSI, providing meaningful information to help guide appropriate intervention initiatives in early adolescence.

In this brief report, we test a hypothesized model in which insecure child-parent attachment acts as a prospective risk factor for NSSI among young adolescents via emotional and behavioral problems.

\section{Method}

\section{Participants and procedure}

Participants were drawn from the JOnG! project, a prospective cohort study of Flemish adolescents, A full description of the procedure and participants has been reported elsewhere (Baetens et al., 2014). The study procedures were approved by the Ethics Committee of all universities cooperating in the JOnG! project. For the current study purposes, we focused on the age $13(\mathrm{~m}=12.71, \mathrm{SD}=0.32)$ and age 14 child-report questionnaires, here after referred to as wave 1 and wave 2. The sample included all 827 individuals that provided valid child-reports at wave 1 ( $57.2 \%$ female). Of these, 559 cases (67.6\% of the sample) also provided data at wave 2 (58.9\% male). None of the 
study variables were related to attrition (all $p>.15)$, and Little's MCAR test $\left(\chi^{2}(6)=\right.$ $6.67, p=.353$ ) was not significant, suggesting that unit-missingness did not impact findings. Expectation maximization was used to account for less than 5\% itemmissingness, a maximum likelihood based approach that estimates values based on all study variables, and is preferable to conventional methods (e.g., list-wise deletion) of handling item-missingness (Schafer \& Graham, 2002).

\section{Measures}

Engagement in NSSI at wave 1 and wave 2 was determined by an affirmative response to the item "Since the previous questionnaire, have you intentionally harmed yourself - e.g. cutting, burning or scratching - without wanting to kill yourself?" Using a single-item measure of NSSI is common in NSSI research and has been shown to render consistent estimates of prevalence (Muehlenkamp et al., 2012).

Children's perceptions of attachment were measured at wave 1 using the Experiences in Close Relationships - Revised Child (ECR-RC) version (Brenning, Soenens, Braet, \& Bosmans, 2011), a child-appropriate adaptation of the Experiences in Close Relationships Scale-Revised (Fraley, Waller, \& Brennan, 2000). The ECR-RC is a child self-report questionnaire comprising 36 items across two subscales: avoidant attachment (avoidance of intimacy and reliance on others; i.e. "I don't like telling my mother how I feel deep down inside”) and anxious attachment (fear of abandonment and rejection, i.e. "I'm afraid my mother will stop loving me"). These subscales showed high internal validity in this sample: avoidant $\alpha=.93$ and anxious $\alpha=.88$. Only items about the child-mother relationship were used in the present study as very few fathers 
participated in the JOnG! project. Although the measure used was child-report, we chose to focus on the child-mother relationship given the preponderant participation of mothers.

Emotional and behavioral problems at wave 1 were measured using the Strengths and Difficulties Questionnaire (SDQ) (Goodman, 2001). The SDQ is a reliable and valid screener of psychological difficulties across different domains (Muris, Meesters, \& van den Berg, 2003; Van Roy, Veenstra, \& Clench-Aas, 2008). For the current study purposes, the child self-report five-item Emotional Symptoms subscale ("I am often impatient, down or in tears" or "I worry a lot") was used to measure emotional problems, and the five-item 'Conduct problems' subscale operationalized behavioral problems ("I often have angry outbursts" or "I do what I am told").

\section{Modeling strategy}

Structural equation modeling was conducted with Mplus v7.4, using robust full maximum likelihood estimation to deal with unit-missingness (Muthén \& Muthén, 2012). The Root Mean Square Error of Approximation (RMSEA) and Standardized Root Mean Square Residual (SRMR) was ûsed to assess the model fit. Values close to 0.08 and 0.05 indicate acceptable and good fit, respectively (Brown, 2015). Using a logistic link function, we fitted an unrestricted structural equation model that included both direct and indirect effects, via emotional and behavioral problems, between avoidant and anxious attachment at wave 1 and NSSI at wave 2. The unrestricted model controlled for the effects of NSSI at wave 1. To arrive at the most parsimonious model underlying our data, effects were constrained to 0 in a restricted model when coefficients failed to reach borderline significance $(p>.08)$, and the lower Bayesian Information Criterion (BIC) of the restricted model indicated it fit the data better (Schwarz, 1978). 


\section{Results}

At wave 1, 827 participants reported on NSSI behavior, of which 23 (2.8\%) reported having engaged in NSSI in the past year. At wave 2, 559 participants reported on NSSI behavior, of which $26(4.7 \%)$ reported having engaged in NSSI in the past year. Girls were more likely than boys to report past year NSSI at both time points (wave 1: $1.7 \%$ versus $3.6 \%$; wave $2: 2.2 \%$ versus $6.4 \%$ ) but this difference only reached statistical significance for wave $2\left(\chi^{2}(559)=5.41, p=.020\right)$. Gender was controlled for as a covariate in subsequent analyses.

The measurement model fit the data well: $\mathrm{RMSEA}=0.051,90 \% \mathrm{CI}=0.049$ $0.053, p=.220 ; \mathrm{SRMR}=0.065$. The unrestricted full structural equation model $(\mathrm{BIC}=$ 108503.8), which freely estimated all coefficients (including indirect effects) indicated that there was no direct effect of higher anxious $(\beta=0.13, \mathrm{SE}=0.46, p=.770)$ or avoidant attachment $(\beta=-0.23, \mathrm{SE}=0.19, p=.221)$ on NSSI at wave 2. Further, there was also no direct association between emotional problems and NSSI at wave 2 ( $\beta=$ $0.64, \mathrm{SE}=1.55, p=.681$ ). These effects were removed in the restricted model (Figure 1), which yielded superior model fit $(\mathrm{BIC}=108470.8)$. As can be seen in Figure $1, \mathrm{NSSI}$ at wave 1 and female gender predicted NSSI at wave 2. Higher anxious (indirect effect: $\beta=$ $0.28, \mathrm{SE}=0.13, p=.031)$ and avoidant attachment (indirect effect: $\beta=0.13, \mathrm{SE}=0.07, p$ $=.045$ ) were indirectly associated with wave 2 NSSI via behavioral problems. 


\section{Figure 1 here}

\section{Discussion}

We found that insecure maternal attachment was indirectly associated with NSSI in young adolescents through behavioral problems. These findings are in keeping with the idea that insecure attachment plays an important role in young adolescent NSSI (Sourander et al., 2006), and that effective behavioral control often fails to develop in the context of insecure attachment (DeKlyen \& Greenberg, 2008). Moreover, our data indicate that insecure attachment may be indirectly related to NSSI through this association with behavioral problems, and that behavioral problems are a major risk factor for NSSI, particularly in young populations. This new finding implies that therapies that strengthen child-parent attachment may be effective in ameliorating these behavioral problems as children learn better communication skills and parents learn to respond more effectively to their children's actions and needs (Moretti, Holland, \& Peterson, 1994). In turn, improvements in attachment security may also reduce risk of NSSI among young adolescents both directly, and indirectly as a result of contingent reductions in behavioral problems. The efficacy of such approaches in preventing NSSI among young adolescents is an important area for future research.

We also found that emotional problems were not associated with NSSI. While this finding is at odds with the large body of research demonstrating that emotional problems are central to NSSI among older adolescents (Nixon, Cloutier, \& Jansson, 2008; Selby, Bender, Gordon, Nock, \& Joiner, 2012), it is nevertheless in keeping with an emerging body of prior NSSI research on young adolescents indicating behavioral problems may be more salient to NSSI than emotional problems in this younger age group (Lundh et al., 
2007; Lundh, Wångby-Lundh, Paaske, Ingesson, \& Bjärehed, 2011; Sourander et al., 2006). While it is possible that NSSI may be one manifestation of the behavioral problems associated with insecure attachment, in the present study behavioral problems were prospectively associated with NSSI, reducing the probability of confounding and reverse causation. These findings suggest that NSSI among young adolescents may be more closely associated with behavioral difficulties than among older adolescents. Our findings underscore the need for a cohort study of the time-variant effect of emotional and behavioral problems on NSSI.

\section{Limitations and future research directions}

Several limitations and future research directions deserve attention. First, although the present sample was larger than most previous longitudinal studies of NSSI with this young age group, the typically low rates of past year NSSI (23 participants at T1 and 26 at T2) precluded more complex model testing (i.e., moderated mediation model); more work is thus warranted. Relatedly, it is important to note that if non-significant direct effects were included, there was no association between attachment and NSSI, highlighting the importance of investigating hypothesized indirect effects even in the absence of a total effect (Hayes, 2009). Therefore, replication of the present finding represents an important goal for future research. Third, because attachment and adjustment (emotional/behavioral symptoms) were measured at the same time point, research with three waves is needed to confirm the temporality of the associations between attachment and behavioral problems. While poor adjustment may be a result of insecure attachment, it is also possible that insecure attachment is at least partially a consequence of the difficulty of parenting poorly adjusted children (Johnston \& Mash, 
2001) A final limitation is that $32 \%$ of the sample did not provide follow-up data, however analysis suggests that baseline variables did not predict attrition and as such results are likely to be generalizable across the initial sample.

Despite these shortcomings, and awaiting future research on this important topic, our data suggest that one possible pathway for the attachment-NSSI association may be through behavioral difficulties, implicating both attachment and behavioral difficulties as possible targets for NSSI treatment and intervention among young adolescents.

\section{Acknowledgement}

The JOnG! study was commissioned, financed and steered by the Ministry of the Flemish Community (Department of Economics, Science and Innovation; Department of Welfare, Public Health and the Family). The work was performed by the Policy Research Centre for Welfare, Public Health and the Family. We gratefully acknowledge the support of the FWO to Dr. Baetens (12M5915N). Matthew Cassels is funded by the Gates Cambridge Trust. 


\section{Works cited}

Ammerman, B. A., Jacobucci, R., Kleiman, E. M., Uyeji, L. L., \& McCloskey, M. S. (2017). The Relationship Between Nonsuicidal Self-Injury Age of Onset and Severity of Self-Harm. Suicide and Life-Threatening Behavior. https://doi.org/10.1111/sltb.12330

Baetens, I., Claes, L., Onghena, P., Grietens, H., Van Leeuwen, K., Pieters, C., ... Griffith, J. W. (2014). Non-suicidal self-injury in adolescence: a longitudinal study of the relationship between NSSI, psychological distress and perceived parenting. $J$ Adolesc, 37(6), 817-826. https://doi.org/10.1016/j.adolescence.2014.05.010

Bowlby, J. (1988). A Secure Base. Parent-Child Attachment and Healthy Human Development. New York: Basic Books.

Brenning, K. M., Soenens, B., Braet, C., \& Bosmans, G. (2011). An adaptation of the Experiences in Close Relationships Scale-Revised for use with children and adolescents. Journal of Social and Personal Relationships, 28(0), 1048-1072. https://doi.org/10.1177/0265407511402418

Brown, T. A. (2015). Confirmatory Factor Analysis for Applied Reaearch. Journal of Chemical Information and Modeling. Guilford Publications. https://doi.org/10.1017/CBO9781107415324.004

Carlson, E. A., \& Sroufe, L. A. (1995). Contribution of attachment theory to developmental psychopathology. John Wiley \& Sons.

Cozolino, L. (2014). The Neuroscience of Human Relationships: Attachment and the Developing Social Brain (Norton Series on Interpersonal Neurobiology) (2nd ed.). New York: WW Norton \& Co. 
DeKlyen, M., \& Greenberg, M. T. (2008). Attachment and psychopathology in childhood. In J. Cassidy \& P. R. Shaver (Eds.), Handbook of attachment: Theory, research, and clinical applications (pp. 637-665). New York: Guilford Press.

Fearon, R. P., Bakermans-Kranenburg, M. J., van IJzendoorn, M. H., Lapsley, A.-M., \& Roisman, G. I. (2010). The Significance of Insecure Attachment and Disorganization in the Development of Children's Externalizing Behavior: AMetaAnalytic Study. Child Development, 81(2), 435-456. https://doi.org/10.1111/j.14678624.2009.01405.x

Fraley, R. C., Waller, N. G., \& Brennan, K. A. (2000). An item response theory analysis of self-report measures of adult attachment. Journal of Personality and Social Psychology, 78(2), 350-365. https://doi.org/10.1037/0022-3514.78.2.350

Franklin, J. C., Ribeiro, J. D., Fox, K. R., Bentley, K. H., Kleiman, E. M., Huang, X., ... Nock, M. K. (2017). Risk factors for suicidal thoughts and behaviors: A metaanalysis of 50 years of research. Psychological Bulletin, 143(2), 187-232. https://doi.org/10.1037/bul0000084

Gandhi, A., Claes, L., Bosmans, G., Baetens, I., Wilderjans, T. F., Maitra, S., ... Luyckx, K. (2016). Non-Suicidal Self-Injury and Adolescents Attachment with Peers and Mother: The Mediating Role of Identity Synthesis and Confusion. Journal of Child and Family Studies, 25(6), 1735-1745. https://doi.org/10.1007/s10826-015-0350-0

Goodman, R. (2001). Psychometric Properties of the Strengths and Difficulties Questionnaire. Journal of the American Academy of Child \& Adolescent Psychiatry, 40(11), 1337-1345. https://doi.org/10.1097/00004583-200111000-00015

Hallab, L., \& Covic, T. (2010). Deliberate Self-Harm: The Interplay Between Attachment 
and Stress. Behaviour Change, 27(2), 93-103. https://doi.org/10.1375/bech.27.2.93

Hankin, B. L., \& Abela, J. R. Z. (2011). Nonsuicidal self-injury in adolescence:

Prospective rates and risk factors in a $2 \frac{1}{2} 2$ year longitudinal study. Psychiatry

Research, 186(1), 65-70. https://doi.org/10.1016/j.psychres.2010.07.056

Hayes, A. F. (2009). Beyond Baron and Kenny: Statistical Mediation Analysis in the

New Millennium. Communication Monographs, 76(4), 408-420. https://doi.org/10.1080/03637750903310360

Irons, C., \& Gilbert, P. (2005). Evolved mechanisms in adolescent anxiety and depression symptoms: the role of the attachment and social rank systems. Journal of Adolescence, 28(3), 325-341. https://doi.org/10.1016/j.adolescence.2004.07.004

Johnston, C., \& Mash, E. J. (2001). Families of Children With AttentionDeficit/Hyperactivity Disorder: Review and Recommendations for Future Research. Clinical Child and Family Psychology Review, 4(3), 183-207. https://doi.org/10.1023/A:1017592030434

Kimball, J. S., \& Diddams, M. (2007). Affect Regulation as a Mediator of Attachment and Deliberate Self-Harm. Journal of College Counseling, 10(1), 44-53. https://doi.org/10.1002/j.2161-1882.2007.tb00005.x

Lundh, L.-G., Karim, J., \& Quillish, E. (2007). Deliberate self-harm in 15-year-old adolescents: A pilot study with a modified version of the Deliberate Self-Harm Inventory. Scandinavian Journal of Psychology, 48(1), 33-41. https://doi.org/10.1111/j.1467-9450.2007.00567.x

Lundh, L.-G., Wångby-Lundh, M., Paaske, M., Ingesson, S., \& Bjärehed, J. (2011). Depressive symptoms and deliberate self-harm in a community sample of 
adolescents: a prospective study. Depression Research and Treatment, 2011(September 2016), 935871. https://doi.org/10.1155/2011/935871

Moretti, M. M., Holland, R., \& Peterson, S. (1994). Long Term Outcome of an Attachment-Based Program for Conduct Disorder. The Canadian Journal of Psychiatry, 39(6), 360-370. https://doi.org/10.1177/070674379403900609

Moretti, M. M., \& Peled, M. (2004). Adolescent-parent attachment: Bonds that support healthy development. Paediatrics and Child Health, 9(8), 551-555.

Muehlenkamp, J. J., Claes, L., Havertape, L., \& Plener, P. L. (2012). International prevalence of adolescent non-suicidal self-injury and deliberate self-harm. Child and Adolescent Psychiatry and Mental Health, 6, 10. https://doi.org/10.1186/1753-20006-10

Muris, P., Meesters, C., \& van den Berg, F. (2003). The Strengths and Difficulties Questionnaire (SDQ). European Child \& Adolescent Psychiatry, 12(1), 1-8. https://doi.org/10.1007/s00787-003-0298-2

Muris, P., Meesters, C., van Mêlick, M., \& Zwambag, L. (2001). Self-reported attachment style, attachment quality, and symptoms of anxiety and depression in young adolescents. Personality and Individual Differences, 30(5), 809-818. https://doi.org/10.1016/S0191-8869(00)00074-X

Muthén, B., \& Muthén, L. (2012). Mplus User's Guide, 7th Edn (6th ed.). Los Angeles. Nixon, M. K., Cloutier, P., \& Jansson, S. M. (2008). Nonsuicidal self-harm in youth: a population-based survey. CMAJ : Canadian Medical Association Journal = Journal de l'Association Medicale Canadienne, 178(3), 306-12. https://doi.org/10.1503/cmaj.061693 
Nock, M. K., \& Favazza, A. R. (2009). Nonsuicidal self-injury: definition and classification (Vol. xiii). Washington, DC.

Papini, D. R., \& Roggman, L. A. (1992). Adolescent Perceived Attachment to Parents in Relation to Competence, Depression, and Anxiety A Longitudinal Study. The Journal of Early Adolescence, 12(4), 420-440. https://doi.org/10.1177/0272431692012004005

Plener, P. L., Schumacher, T. S., Munz, L. M., \& Groschwitz, R. C. (2015). The longitudinal course of non-suicidal self-injury and deliberate self-harm: a systematic review of the literature. Borderline Personality Disorder and Emotion Dysregulation, 2, 2. https://doi.org/10.1186/s40479-014-0024-3

Schafer, J. L., \& Graham, J. W. (2002). Missing Data: Our View of the State of the Art. Psychological Methods, 7(2), 147-177. https://doi.org/10.1037//1082-989X.7.2.147

Schwarz, G. (1978). Estimating the Dimension of a Model. The Annals of Statistics, 6(2), 461-464. https://doi.org/10.1214/AOS/1176344136

Selby, E. A., Bender, T. W., Gôrdon, K. H., Nock, M. K., \& Joiner, T. E. (2012). Nonsuicidal self-injury (NSSI) disorder: A preliminary study. Personality Disorders: Theory, Research, and Treatment, 3(2), 167-175. https://doi.org/10.1037/a0024405 Sourander, A., Aromaa, M., Pihlakoski, L., Haavisto, A., Rautava, P., Helenius, H., \& Sillanpää, M. (2006). Early predictors of deliberate self-harm among adolescents. A prospective follow-up study from age 3 to age 15. Journal of Affective Disorders, 93(1-3), 87-96. https://doi.org/10.1016/j.jad.2006.02.015

Swannell, S. V., Martin, G. E., Page, A., Hasking, P., \& St John, N. J. (2014). Prevalence of nonsuicidal self-injury in nonclinical samples: Systematic review, meta-analysis 
and meta-regression. Suicide and Life-Threatening Behavior, 44(3), 273-303. https://doi.org/10.1111/sltb.12070

Tatnell, R., Hasking, P., Newman, L., Taffe, J., \& Martin, G. (2016). Attachment, Emotion Regulation, Childhood Abuse and Assault: Examining Predictors of NSSI Among Adolescents. Archives of Suicide Research, 1-11. https://doi.org/10.1080/13811118.2016.1246267

Tatnell, R., Kelada, L., Hasking, P., \& Martin, G. (2014). Longitudinal analysis of adolescent NSSI: The role of intrapersonal and interpersonal factors. Journal of Abnormal Child Psychology, 42(6), 885-896. https://doi.org/10,1007/s10802-0139837-6

Van Roy, B., Veenstra, M., \& Clench-Aas, J. (2008). Construct validity of the five-factor Strengths and Difficulties Questionnaire (SDQ) in pre-, early, and late adolescence. Journal of Child Psychology and Psychiatry, 49(12), 1304-1312. https://doi.org/10.1111/j.1469-7610.2008.01942.x

Wilkinson, P. O., Kelvin, R., Roberts, C., Dubicka, B., \& Goodyer, I. (2011). Clinical and Psychosocial Predictors of Suicide Attempts and Nonsuicidal Self-Injury in the Adolescent Depression Antidepressants and Psychotherapy Trial (ADAPT). American Journal of Psychiatry, 168(5), 495-501. https://doi.org/10.1176/appi.ajp.2010.10050718

Yates, T. M., Tracy, A. J., \& Luthar, S. S. (2008). Nonsuicidal self-injury among \&quot;privileged\&quot; youths: longitudinal and cross-sectional approaches to developmental process. Journal of Consulting and Clinical Psychology, 76(1), 5262. https://doi.org/10.1037/0022-006X.76.1.52 


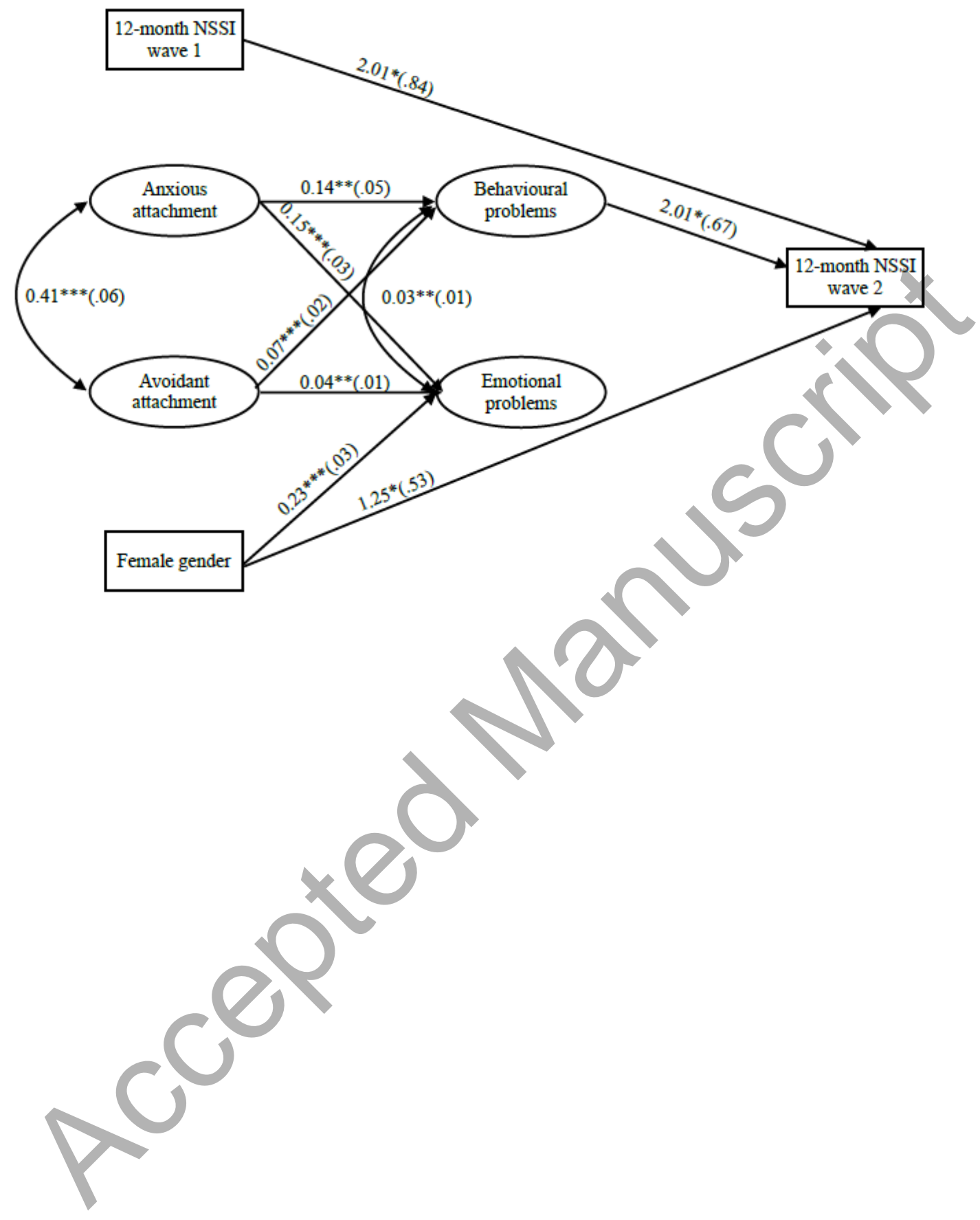

